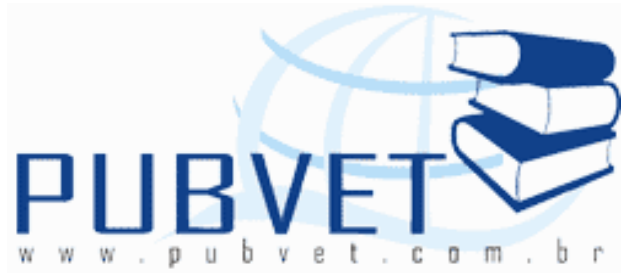

PUBVET, Publicações em Medicina Veterinária e Zootecnia.

\title{
Utilização de fitase na alimentação de aves e suínos
}

Bruno Andreatta Scottá ${ }^{1}$, Ana Paula Cardoso Gomide ${ }^{1}$, Priscila Furtado

Campos $^{1}$, Carlota Coelho Barroca ${ }^{1}$, Andressa da Silva Formigoni ${ }^{2}$, Soraia Viana

Ferreira $^{3}$

${ }^{1}$ Doutorando (a) do Programa de Pós-Graduação em Zootecnia da Universidade Federal de Viçosa - UFV.

${ }^{2}$ Doutoranda do Programa de Pós-Graduação em Zootecnia da Universidade Federal de Minas Gerais - UFMG.

3Estudante de Graduação do Instituto Federal de Educação, Ciência e Tecnologia do Sudeste de Minas Gerais - Campus Rio Pomba

\section{Resumo}

Esta revisão teve como objetivo demonstrar o modo de ação e os benefícios da utilização da enzima fitase na nutrição e alimentação de aves e suínos. O ácido fítico é uma molécula que serve como reserva de fósforo para os vegetais e microrganismos, o fósforo contido nessa molécula está indisponível para as aves e suínos, pois eles possuem pequena produção da enzima fitase que degrada o ácido fítico. O uso de fitase exógena na alimentação de aves e suínos pode auxiliar na liberação do fósforo antes indisponível para os animais, e com isso diminuir a inclusão de fósforo inorgânico nas dietas e também diminuir a excreção de fósforo para o ambiente, já que ele apresente grande poder poluente. Além de disponibilizar o fósforo fítico para os animais, a fitase 
SCOTTÁ, B.A. et al. Utilização de fitase na alimentação de aves e suínos. PUBVET, Londrina, V. 8, N. 2, Ed. 251, Art. 1660, Janeiro, 2014.

também auxilia na liberação de outros minerais como o cálcio, cobre, zinco, cobalto, manganês e ferro, assim como aminoácidos e proteínas que podem se encontrar complexados à molécula de ácido fítico e assim indisponíveis para os animais.

Palavras-chave: ácido fítico, fósforo, minerais

\section{Use of phytase in feed for poultry and swine}

\section{Abstract}

This review aimed to demonstrate the mode of action and benefits of the use of phytase in nutrition and feeding of poultry and pigs. Phytic acid is a molecule which serves as a reserve of phosphorus for plants and microorganisms, phosphorus contained in that molecule is unavailable to birds and swine, because they have small production of phytase to degrade the phytic acid. The use of exogenous phytase in pig and poultry feed can assist in the release of phosphorus unavailable to the animals before, and thus decrease the inclusion of inorganic phosphorus in diets and also decrease the excretion of phosphorus to the environment, as it presents a great polluting power. In addition make available to the phytic acid for animal, the phytase also assists in the release of other minerals such as calcium, copper, zinc, cobalt, manganese and iron, as well as amino acids and proteins may be found complexed with phytic acid molecule and thereby unavailable to animals.

Keywords: minerals, phosphorus, phytic acid

\section{Introdução}

No Brasil, a maioria das dietas para suínos e aves é composta por ingredientes de origem vegetal, em especial milho e soja, onde representam cerca de $90 \%$ da dieta, contribuindo substancialmente para satisfazer as necessidades em energia, proteínas, minerais e vitaminas de acordo com as tabelas e recomendações de exigências nutricionais para estes animais. 
SCOTTÁ, B.A. et al. Utilização de fitase na alimentação de aves e suínos. PUBVET, Londrina, V. 8, N. 2, Ed. 251, Art. 1660, Janeiro, 2014.

Como a nutrição corresponde a aproximadamente $70 \%$ dos custos de produção desta atividade, é crescente a busca por alternativas que minimizem estes custos.

Os nutrientes, em grande parte, encontram-se nos tecidos e estruturas celulares, compondo macromoléculas como proteínas, gorduras ou açúcares complexos, esses nutrientes não podem ser absorvidos diretamente, eles devem ser hidrolizados por enzimas específicas, transformando-os em estruturas que podem ser absorvidos e aproveitados pelo animal para as suas necessidades de manutenção, crescimento e reprodução.

A biodisponibilidade de um determinado alimento refere-se à porção que pode ser utilizada pelo animal para satisfazer as funções para os quais esse elemento é necessário. Este processo não é simples e envolve equilíbrio biológico de uma flora microbiana ativa, processos biológicos e físico-químicos que devem ocorrer de forma coordenada e equilibrada para uma digestão eficiente e que promova saúde e bem estar animal (Sklan et al., 2002).

É imprescindível que se estude a digestibilidade dos nutrientes, possibilitando a formulação de rações de forma mais eficientes e econômicas (Strada et al., 2005). Segundo Bertechini (2006), o desenvolvimento biotecnológico permitiu que se produzissem enzimas altamente especializadas e com objetivos importantes para complementação das enzimas digestivas endógenas produzidas no trato digestório dos animais. Os ingredientes vegetais possuem fatores antinutricionais e/ou substancias que não são normalmente digeridas pelas enzimas e o uso de enzimas específicas, permite a melhoria do aproveitamento destes compostos.

O objetivo desta revisão foi expor a ação e os benefícios da utilização da enzima fitase na nutrição e alimentação de aves e suínos.

\section{2. Ácido Fítico}

O fósforo pode ser de origem animal, vegetal ou mineral, sendo a fonte um fator determinante no aproveitamento, nos custos e mesmo na excreção. 
SCOTTÁ, B.A. et al. Utilização de fitase na alimentação de aves e suínos. PUBVET, Londrina, V. 8, N. 2, Ed. 251, Art. 1660, Janeiro, 2014.

Considera-se que fontes de origem animal apresentam $100 \%$ de biodisponibilidade, quando comparadas à fonte padrão que seria o fosfato bicálcico (mineral). Por outro lado, estima-se que aproximadamente $70 \%$ do fósforo do milho e $60 \%$ do fósforo contido no farelo de soja estejam na forma de fósforo fítico.

Cerca de $2 / 3$ do fósforo contido nos ingredientes de origem vegetal estão numa forma indisponível para o animal, porque ele se encontra ligado ao inositol, formando a molécula do ácido fitico ou hexafosfato de inositol, molécula esta que pode formar complexos orgânicos com minerais nutricionalmente importantes, como o cálcio, zinco, manganês, cobre e ferro, representando um dos principais fatores antinutricionais que afetam a disponibilidade desses minerais além de proteínas e energia para os animais monogástricos.

O ácido fítico também conhecido como fitato é um complexo de cálcio ou magnésio com o mio-inositol, e constitui-se na principal forma de armazenamento de fósforo pela maioria dos vegetais.

O fitato é considerado um fator antinutricional para os monogátricos, pois ao se ligar ao fósforo e/ou a outros nutrientes importantes como proteínas e aminoácidos, diminui a disponibilidade destes para o organismo (Selle et al., 2007).

A molécula do ácido fítico possui seis carbonos ligados a seis grupos fosfatos que podem conter em $\mathrm{pH}$ neutro um ou dois oxigênios negativamente carregados. Estes oxigênios que são responsáveis por quelatar os cátions como $\mathrm{Cu}^{2+}, \mathrm{Zn}^{2+}, \mathrm{Co}^{2+}, \mathrm{Mn}^{2+}, \mathrm{Fe}^{3+}$ e $\mathrm{Ca}^{2+}$ (Faria et al., 2006).

A concentração de ácido fítico nos vegetais pode variar de acordo com o estágio de maturidade da planta, o grau de processamento, o cultivar, os fatores climáticos durante a produção e o tipo do solo onde a cultura foi instalada (Manangi \& Coon, 2006).

Nas rações animais a concentração de fitato varia de 2,5 a $4 \mathrm{~g}$ por quilo de ração, e o conteúdo de fósforo neste está em torno de $282 \mathrm{~g}$ por quilograma de ácido fítico (Ravindram et al., 1995). Assim, a disponibilização deste 
SCOTTÁ, B.A. et al. Utilização de fitase na alimentação de aves e suínos. PUBVET, Londrina, V. 8, N. 2, Ed. 251, Art. 1660, Janeiro, 2014.

conteúdo de fósforo, presente nos principais ingredientes utilizados na formulação de dietas animais, poderia suprir parte da exigência diária de fósforo para monogástricos. Além do fósforo outros minerais, aminoácidos e proteínas quelatados ao fitato quando disponibilizados contribuem para melhorar o desempenho dos animais.

\section{Fitase}

A fitase é uma enzima que catalisa a liberação do fosfato da molécula de fitato. Segundo Vats \& Banerjee (2004) existem dois tipos de fitases: a 3fitase a 6-fitase. A 6-fitase é capaz de desfosforilar completamente o ácido fítico, enquanto a 3-fitase não hidrolisa o fosfomonoester. Normalmente, a 3fitase é uma enzima sintetizada por microorganismos enquanto a 6-fitase é sintetizada pelas plantas (Turk et al., 2000).

A atividade da enzima fitase é medida pela capacidade desta em liberar fósforo complexado ao fitato. Normalmente é atribuída a atividade a terminologia unidades de fitase (FTU), que representa a quantidade de enzima necessária para liberar 1 micromol de fósforo inorgânico por minuto a 5,1 mM (substrato de sódio-fitato) em pH 5,5 e temperatura $37^{\circ} \mathrm{C}$ (Engelen et al., 1994).

A enzima fitase é amplamente distribuída em plantas, animais e microorganismos, sendo descritas na literatura quatro fontes distintas desta: fitase intestinal (encontrada em secreções digestivas); fitase originada de microorganismos no trato gastrintestinal; fitase endógena (presente nas plantas); fitase exógena (sintetizada por microorganismos e com finalidade comercial).

A fitase é produzida em grande quantidade por plantas e microrganismos, mas os animais a produzem em pequenas quantidades, o que torna importante sua disponibilização na dieta para auxiliar na utilização do fosforo complexado à molécula de fitato. 
SCOTTÁ, B.A. et al. Utilização de fitase na alimentação de aves e suínos. PUBVET, Londrina, V. 8, N. 2, Ed. 251, Art. 1660, Janeiro, 2014.

A fitase para uso industrial é insetizada por vários grupos de organismos, como: fungos (Aspergillus niger, Aspergillus ficcum, Aspergillus oryzae), bactérias (Bacillus subtilis, Escherichia coli, Klebsiella aerogenes Corynebactrium bovis, Pseudomonas sps.) e leveduras (Saccharomyces cerevisiae, Schwanniomyces castellii) (Singh, 2008).

Os estudos da enzima fitase começaram na década de 60, mas foi somente a partir do início da década de 90 que se iniciou a produção comercial da fitase produzida pelo fungo Aspergillus niger, o incentivo para sua produção comercial ocorreu quando do surgimento de legislações que visavam controlar a poluição por fosfatos em unidades de criação de suínos e aves.

As fitases vegetais são ativas em pH próximo a 5, sendo muito sensíveis a variações no $\mathrm{pH}$. Dessa forma, meios muito ácidos ou muito alcalinos podem inativá-las de maneira irreversível, ou seja, como o pH do estomago dos monogástrico é muito baixo, não permite a ativação da enzima e também pode inativa-la.

Kim et al. (2006) conseguiram diminuir o pH de atividade máxima da fitase do $A$. niger de 5,5 para 3,8, o que é mais coerente com o pH do estômago do suíno. Como resultado, a degradação in vitro de fitato de soja aumentou 2,7 vezes. Com isso, concluiu-se que mudando o perfil do $\mathrm{pH}$ da fitase do Aspergillus niger para coincidir com o pH do estômago do suíno aumentou-se sua eficácia como aditivo para alimentação animal.

Ruminantes digerem o fitato pela ação de fitases produzidas pela flora microbiana do rúmen, sendo que o fosfato inorgânico hidrolisado do fitato é utilizado tanto pelo ruminante quanto pelos microrganismos. Porém, essa situação é diferente com animais monogástricos. O rato possui uma alta atividade de fitase, da ordem de $30 \mathrm{mUI} / \mathrm{mg}$ de proteínas da mucosa do intestino delgado, já os suíno possui atividade de 0,5 a 1,5 mUI/mg.

A capacidade de hidrolisar o fitato no trato digestório dos animais monogástricos pode ser influenciada por vários fatores, entre os quais se destacam a variação do $\mathrm{pH}$, da umidade, da temperatura, a presença de certos 
SCOTTÁ, B.A. et al. Utilização de fitase na alimentação de aves e suínos. PUBVET, Londrina, V. 8, N. 2, Ed. 251, Art. 1660, Janeiro, 2014.

minerais como cálcio e de outras enzimas, além do tempo de passagem da digesta (Haefner et al., 2005).

O principal problema em utilizar as fitases, sejam as adicionadas à ração ou aquelas presentes naturalmente nos cereais, é a sua conservação no curso da fabricação dos alimentos. Um aquecimento muito intenso durante a granulação $\left(70\right.$ a $80^{\circ} \mathrm{C}$ ) leva a perdas importantes de atividade da fitase (30 a $50 \%$, e perto de $100 \%$ quando o aquecimento passa dos $80^{\circ} \mathrm{C}$ ). Para o trigo, milho e triticale, a atividade ótima está em torno $50^{\circ} \mathrm{C}$ (Pointillart, 1994).

Outro fator que afeta a eficácia da fitase na ração para suínos é a fonte de fitato na ração. Dekker et al. (1992) estudaram o efeito de duas fontes de fitato na eficácia da fitase microbiana. As dietas foram à base de milho e de farelo de girassol. Foi observado que o alto nível de fitato nas dietas à base de milho gerou substancialmente uma quantidade maior de fósforo digestível e que o fitato do milho é mais facilmente disponível que o fitato do farelo de girassol. No trigo, cevada e arroz a atividade da fitase é alta, entretanto, o milho e o farelo de soja, contêm pouca ou nenhuma atividade (Selle, 1997).

\section{Benefícios da utilização de fitase}

\subsection{Disponibilidade de fósforo e cálcio}

A adição de fitase exógena às dietas de monogástricos hidrolisa as ligações entre o oxigênio presente no esqueleto carbônico e o fósforo aumentando a disponibilidade deste e dos demais minerais e/ou compostos ligados ao fitato.

O fósforo hidrolisado pode ser utilizado pelos animais como o fósforo inorgânico e atuar nas diversas funções orgânicas. Entretanto, a hidrólise do fósforo é variável (3-42\%), dependendo da capacidade fisiológica animal em realizar este processo e também da concentração de cálcio na dieta (Ballam et al., 1984), dada sua participação na retenção do fósforo. Apesar de o cálcio ser o cátion bivalente com menor poder de quelatação com o fitato, é o 
SCOTTÁ, B.A. et al. Utilização de fitase na alimentação de aves e suínos. PUBVET, Londrina, V. 8, N. 2, Ed. 251, Art. 1660, Janeiro, 2014.

responsável pelo maior impacto negativo na nutrição mineral de monogástricos, pois sua biodisponibilidade afeta o requerimento nutricional de outros minerais.

O cálcio é um dos principais responsáveis por diminuir a eficiência da fitase em monogástricos, pois este em grande concentração na dieta complexa-se com o fitato e levando a sua precipitação no trato gastrintestinal o que impede a ação da fitase. O mesmo ocorre quando a relação cálcio:fósforo ou o nível de fósforo inorgânico na dieta são altos.

Existem três teorias que tentam explicar a menor eficiência da fitase de acordo com a maior concentração de cálcio da dieta. A primeira sugere que o cálcio forma um complexo insolúvel com o fitato impedindo a ação da fitase (Wise, 1983). A segunda aponta o meio desfavorável para atividade da enzima criado pelo cálcio no pH intestinal (Nelson, 1967). E a terceira aponta a competição exercida pelo cálcio em excesso e a enzima por mesmos sítios de absorção (Qian et al., 1995).

Mohammed et al. (1991) trabalhando com aves em crescimento encontraram aumento de $15 \%$ na quantidade de fósforo fítico hidrolisado quando reduziram o teor de cálcio da dieta de 1 para 0,5\%. Catalá-Gregori et al. (2007) afirmam que dietas com moderados ou baixos níveis de cálcio suplementadas com fitase tendem a aumentar a retenção de fósforo em frangos de corte machos.

Igbasan et al. (2000) estudando fitases microbianas derivadas do $A$. niger e da $E$. coli melhoraram a digestibilidade total de fósforo (33-34\%) e de cálcio (18-20\%) em leitões que recebiam dietas à base de milho e soja.

Brana et al. (2006) compararam a eficácia de fitases derivadas do $A$. niger e da $E$. coli em dietas para suínos com níveis reduzidos de fósforo por um período de 130 dias, e verificaram que $500 \mathrm{FTU} / \mathrm{kg}$ da $E$. coli melhorou o ganho de peso em 9,9\% e a eficiência alimentar em $8 \%$, enquanto $500 \mathrm{FTU} / \mathrm{kg}$ do $A$. niger melhorou em $9,5 \%$ e $6 \%$ essas características respectivamente.

De acordo com Quian et al. (1996), a suplementação com fitase em rações para suínos deve ocorrer quando esta apresenta uma relação $\mathrm{Ca}: \mathrm{P}$ o 
SCOTTÁ, B.A. et al. Utilização de fitase na alimentação de aves e suínos. PUBVET, Londrina, V. 8, N. 2, Ed. 251, Art. 1660, Janeiro, 2014.

mais baixa possível, próxima a 1,2:1. Quando a relação molar de cátions (cálcio ou fósforo) estiver acima de $2: 1$ ou $3: 1$, a formação do complexo insolúvel torna-se maior. Como consequência, a formação dos cristais de fitato diminui a acessibilidade da enzima fitase.

Cromwell et. al (1995) observaram que suínos em crescimento e terminação alimentados com níveis decrescentes de $\mathrm{P}$, apresentaram diminuição da quantidade de cinzas no osso e de $\mathrm{P}$ nas fezes. Os autores ainda verificaram melhora na conversão alimentar, aumento no consumo alimentar, na velocidade de crescimento e na resistência à quebra dos ossos.

\subsection{Disponibilidade de outros minerais}

$\mathrm{O}$ ácido fítico pode se complexar com inúmeros cátions bivalentes $\left(\mathrm{Cu}^{2+}\right.$, $\mathrm{Zn}^{2+}, \mathrm{Co}^{2+}, \mathrm{Mn}^{2+}, \mathrm{Fe}^{3+}$ e $\mathrm{Ca}^{2+}$ ) tornando-os biologicamente indisponíveis para os monogástricos. Quando se utiliza a suplementação de fitase endógena vários desses cátions podem ser novamente disponibilizados (Singh, 2008).

A suplementação dietética de fitase pode aumentar a utilização do zinco complexado ao fitato, elevando em até $30 \%$ sua retenção por frangos de corte (Yi et al., 1996).

Mohanna \& Nys (1999) trabalhando com dietas a base de milho e soja verificaram que a adição de $800 \mathrm{FTU} / \mathrm{kg}$ de fitase permitiu a redução de até 14 $\mathrm{mg} / \mathrm{kg}$ de zinco em rações formuladas para frangos de corte.

Sebastian et al. (1996) verificaram que a suplementação de fitase em dietas à base de milho e farelo de soja com baixos níveis de fósforo inorgânico aumentou a retenção de cobre em frangos. Já Mohanna \& Nys (1999) relataram melhora na utilização de manganês devido à suplementação de fitase no mesmo tipo de animais.

Liu et al. (2010) afirmam que a utilização da enzima fitase em rações formuladas para frangos de corte na fase de crescimento, reduz o fluxo ileal de manganês, ferro e potássio nestes animais, o que evidencia melhor aproveitamento desses minerais. 
SCOTTÁ, B.A. et al. Utilização de fitase na alimentação de aves e suínos. PUBVET, Londrina, V. 8, N. 2, Ed. 251, Art. 1660, Janeiro, 2014.

\subsection{Disponibilidade de proteínas e aminoácidos}

O ácido fítico assim como ocorre com minerais pode se complexar com proteínas e/ou aminoácidos tornando estes indisponíveis para os animais. A complexação do fitato com proteínas pode gerar dois tipos de compostos diferentes, os binários (fitato-proteína) ou os terciários (fitato-mineralproteína), dependendo do $\mathrm{pH}$ do meio. Os compostos binários são formados em pH ácido e os terciários em pH próximo da neutralidade (Singh, 2008).

Além da ligação com as proteínas o ácido fítico pode se complexar diretamente com aminoácidos livres no intestino diminuindo a disponibilidade destes. Ruterford et al. (1997) verificaram in vitro uma diminuição de $22 \%$ na disponibilidade de aminoácido lisina quando incubaram este com farelo de arroz (fonte de fitato utilizado). Quando adicionaram fitase à mistura a perda de lisina foi de apenas $9 \%$, o que sugere que há interação entre o fitato e o aminoácido lisina.

O menor aproveitamento das proteínas pelas aves quando alimentadas com rações contendo maior concentração de fitato também pode estar relacionado à menor atividade das enzimas pepsina e tripsina. De acordo com Singh (2008) a proteólise pode ser inibida pela complexação do fitato com a pepsina e tripsina, alterando a configuração destas, e o mineral cálcio é o principal responsável por este processo de quelatação. Além dessas enzimas, também a a-amilase tem sua atividade alterada pela complexação com o fitato.

A adição de fitase exógena é uma prática eficaz para reduzir a perda endógena e aumentar a absorção intestinal dos aminoácidos dietéticos diminuindo sua complexação com o fitato (Cowieson et al., 2008).

Catalá-Gregori et al. (2007) verificaram em frangos de corte aumento na retenção aos 21 dias e maior digestibilidade ileal aparente aos 42 dias de proteína bruta quando suplementaram rações à base de trigo e farelo de soja com $600 \mathrm{FTU} / \mathrm{kg}$ de ração de fitase. 
SCOTTÁ, B.A. et al. Utilização de fitase na alimentação de aves e suínos. PUBVET, Londrina, V. 8, N. 2, Ed. 251, Art. 1660, Janeiro, 2014.

Gomide et al. (2007) afirmaram que para frangos de corte na fase de 22 a 42 dias é possível reduzir o nível de proteína bruta na ração para $16 \%$ quando suplementa-se esta com fitase e aminoácidos industriais. De acordo com Lan et al. (2010) a adição de 250 a 1000 FTU/kg de ração de fitase melhora a digestibilidade da proteína bruta no trato gastrointestinal de frangos de corte.

Mroz et al. (1994), utilizando $800 \mathrm{FTU} / \mathrm{kg}$ de fitase microbiana, observaram aumento de 2,3\% na digestibilidade de proteína bruta para suínos. Ketaren et al. (1993), trabalhando dietas suplementadas com $1000 \mathrm{FTU} / \mathrm{kg}$ para fêmeas suínas, verificaram um aumento na deposição de proteínas e lipídios. Entretanto, existem outros estudos que não demonstraram efeito da fitase microbiana sobre a digestibilidade de aminoácidos e proteína bruta (Valaja et al., 1998).

\subsection{Melhora na utilização da energia do alimento}

A suplementação de Fitase também proporciona uma melhora na utilização da energia do alimento. Isto é esperado devido ao melhor aproveitamento da proteína complexada ao fitato. Kies et al. (2001) afirmam que em média a adição $500 \mathrm{FTU} / \mathrm{kg}$ de ração de fitase disponibilizam aproximadamente $2 \mathrm{~g}$ de proteína bruta digestível adicionais na ração.

Outro aspecto interessante em relação ao aproveitamento da energia, diz respeito à utilização de ácidos graxos. De acordo com Liu et al. (2010) a fitase exógena pode modificar a digestibilidade e síntese de ácidos graxos, a atividade da enzima lipase, os níveis de lipídeos e leptina no plasma e fígado, e consequentemente influenciar os processos de digestão e deposição de gordura em frangos de corte.

Em codornas a fitase promove aumento na utilização de energia devido a melhora na digestibilidade das proteínas (Lima, 2008), possivelmente porque os minerais complexados com o fitato e os lipídeos, no intestino, formam reações de saponificação, prejudicando a absorção destes lipídeos (Ravindran 
SCOTTÁ, B.A. et al. Utilização de fitase na alimentação de aves e suínos. PUBVET, Londrina, V. 8, N. 2, Ed. 251, Art. 1660, Janeiro, 2014.

et al., 2000). Lima, (2008) conclui que o nivel de $368 \mathrm{FTU} / \mathrm{kg}$, é o ideal para melhorar o aproveitamento de energia e a retenção de nitrogênio (conseqüência da menor excreção de $\mathrm{N}$ ) em dietas para codorna japonesa em postura.

\section{Conclusão}

A adição de fitase permite a disponibilização de uma grande quantidade de nutrientes, que estão complexados à molécula de ácido fítico, permitindo assim uma redução da adição desses nutrientes na ração, diminuindo assim os custos de produção e a poluição ambiental, devido a menor excreção de nutrientes com alto poder poluente.

\section{Referências Bibliográficas}

BALLAM, G.C.; NELSON, T.S.; KIRBY, L.K. et al. Effect of fiber and phytate source and of calcium and phosphorus level on phytate hydrolysis in the chick. Poultry Science, v.63, p.333-338, 1984.

BEERS, S.; JONGBLOED, A.W. Apparent overall (total tract) digestibility of $\mathrm{P}$ in relation to doses of Aspergillus niger phytase in diets for pigs. Journal of Animal Science, v.70 (Suppl.1), p.242, 1992.

BERTECHINI, A.G. Nutrição de monogástricos. Lavras: Ed. UFLA, 2006. 301p.

BRANA, D.V.; ELLIS, M.; CASTANEDA, E.O. et al. Effect of a novel phytase on growth performance, bone ash, and mineral digestibility in nursery and grower-finisher pigs. Journal of Animal Science, v.84, p.1839-1849, 2006.

CATALÁ-GREGORI, P.; GARCÍA, V.; MADRID, J. et al. Response of broilers to feeding lowcalcium and total phosphorus wheat-soybean based diets plus phytase: Performance, digestibility, mineral retention and tibiotarsus mineralization. Canadian Journal of Animal Science, v.87, p.563-569, 2007.

COWIESON, A.J.; RAVINDRAN, V.; SELLE, P.H. et al. Influence of Dietary Phytic Acid and Source of Microbial Phytase on Ileal Endogenous Amino Acid Flows in Broiler Chickens. Poultry Science, v.87, p.2287-2299, 2008.

CROMWELL, G.L. COFFEY, R.D., PARKER, G.R., et al., Efficacy of a recombinant-derived phytase in improving the bioavailability of phosphorus in corn-soybean meal diets for pigs. Jornal of Animal Science, v.73, n.7, p.2000-2008, 1995.

DEKKER, R.A.; KEMME, P.A.; JONGBLOED, A.W. Methodological comparison of the assessment of $P$ digestibility of tapioca and maize, and the influence of amount and origin of phytic acid on the efficacy of microbial phytase from Aspergillus niger. Report IVVO-DLO, n. 244, 1992. 
ENGELEN, A.J.; VAN DER HEEH, F.C.; RANDSDORP, P.G.H. et al. Simple and rapid determination of phytase activity. Journal of AOAC International, v.77, p.760-764, 1994.

FARIA, O.L.V.; KOETZ, P.R.; SANTOS, M.S. et al. Remoção de fósforo de efluentes da parboilização de arroz por absorção biológica estimulada em reator em batelada seqüencial (RBS). Ciênc. Tecnol. Aliment, v.26, p.309-317, 2006.

GOMIDE, E.M.; RODRIGUES, P.B.; FREITAS, R.T.F. et al. Planos nutricionais com a utilização de aminoácidos e fitase para frangos de corte mantendo o conceito de proteína ideal nas dietas. Revista Brasileira de Zootecnia, v.36, p.1769-1774, 2007.

HAEFNER, S.; KNIETSCH, A.; SCHOLTEN, E. et al. Biotechnological production and applications of phytases. Applied Microbiology and Technology, v.68, n.5, 2005.

IGBASAN, F.A.; SIMON, O.; MILKSCH, G. et al. Comparative studies of the in vitro properties of phytases from various microbial origins. Archives of Animal Nutrition, v.53, p.353-373, 2000.

KETAREN, P.P.; BATTERHAM, E.S.; DETTMANN, E.B. et al. Phosphorus studies in pigs. 3. Effect of phytase supplementation on the digestibility and availability of phosphorus in soyabean meal for grower pigs. British Jornal of Nutrition, v.70, p.289-311, 1993.

KIES, A.K.; VAN HEMERT, K.H.F; SAUCER, W.C. et al. Effect of phytase on protein and amino acid digestibility and energy retention. World's Poultry Science Journal, v.57, p.109-126, 2001.

KIM, T.; MULLANEY, E. J.; PORRES, J. M. et al. Shifting the ph profile of Aspergillus niger phya phytase to match the stomach ph enhances its effectiveness as an animal feed additive. Applied and Environmental Microbiology, v.72, n.6, p.4397-4403, 2006.

LAN, G.Q.; ABDULLAH, N.; JALALUDIN, S.; HO, Y.W. et al. In vitro and in vivo enzymatic dephosphorylation of phytate in maize-soya bean meal diets for broiler chickens by phytase of Mitsuokella jalaludinii. Animal Feed Science and Technology, v.158, p.155-164, 2010.

LIMA H.J.A. Uso da enzima fitase em ração para codornas japonesas em postura. Viçosa, MG: Universidade Federal de Viçosa, 2008. Disertação (Mestrado em Zootecnia) - Universidade Federal de Viçosa, 2008.

LIU, N.; RU, Y.; WANG, J.; XU, T. et al. Effect of dietary sodium phytate and microbial phytase on the lipase activity and lipid metabolism of broiler chickens. British Journal of Nutrition, v.103, p.862-868, 2010.

MANANGI, M.K. \& COON, C.K. Evaluation of phytase enzyme with chicks fed basal diets containing different soyabean meal samples. Journal of Applied Poultry Research, v.15, p.292-306, 2006.

MOHAMMED, A.; GIBNEY, M.J.; TAYLOR, T.G. et al. The effect of dietary levels of inorganic phosphorus, calcium and cholecalciferol on the digestibility of phytate phosphorus by the chick. British Journal of Nutrition, v.66, p.251-259, 1991.

MOHANNA, C. \& NYS, N. Changes in zinc and manganese availability in broilers chicks induced by vegetal and microbial phytase. Animal Feed Science and Technology, v.77, p.241-253, 1999.

MROZ, Z.; JONGBLOED, A.W.; KEMME, P.A. Apparent digestibility and retention of dietary nutrients bound to phytase complexes as influenced by microbial phytase and feeding regimen in pigs. Journal of Animal Science, v.72, p.126-132, 1994.

NELSON, T.S. The utilization of phytate phosphorus by poultry: a review. Poultry Science, v.46, p.862-871, 1967.

POINTILLART, A. Phytates, phytases: leur importance dans l'alimentation des monogastriques. INRA Productions Animales, v.7, p.29-39, 1994. 
QUIAN, H.; KORNEGAY, E. T.; CONNER JR., D. E. Adverse effects of wide calcium: phosphorus ratios on supplemental phytase. Efficacy for weanling pigs fed two dietary phosphorus levels. Journal of Animal Science, v.74, n.6, p.1288-1297, 1996.

QIAN, H.; KORNEGAY, E.T.; DENBOW, D.W. et al. Utilization of phytate phosphorus and calcium as influenced by microbial phytase, vitamin D3 and the calcium: total phosphorus ratios in broiler diets. Poultry Science, v.74, (Suppl.1) p.126, 1995.

RAVINDRAN, V.; CABAHUG, S.; RAVINDRAN, G. et al. Influence of microbial phytase on apparent ileal amino acid digestibility of feedstuffs for broilers. Poultry Science, v.78, n.5, p.699-706, 2000.

RAVINDRAN, V.; BRYDEN, W.L.; KONERGAY, E.T. et al. Phytases: occurrence, bioavailability and implications in poultry nutrition. Poultry and Avian Biology Revews, v.6, p.125-143, 1995.

RUTHERFORD, S.M.; EDWARDS, E.C.A.; SELLE, P.H. et al. Effect of phytase on lycine-rich polard complexes. In: CRANWELL, P.D. (Ed) Manipulating Pig Production. Anais... Werribee, Victoria: Australasian Pig Science Association, 1997.

SELLE, P.H.; RAVINDRAN, V. Microbial phytase in poultry nutrition. Animal Feed Science and Technology, v.135, n.1-2, p.1-41, 2007.

SELLE, P.H. The potential of microbial phytase the sustainable production of pigs and poultry. In: 7th Short Course and Feed Technology. Proceedings...Korea: Korean Society of Animal Nutrition and feedstuffs, 1997. p.124.

SEBASTIAN, S.; TOUCHBURN, S.P.; CHAVEZ, E.R.; et al. The effects of supplemental microbial phytase on the performance and utilization of dietary calcium, phosphorus, copper and zinc in broiler chickens fed corn-soyabean diets. Poultry Science, v.75, p.729-736, 1996.

SINGH, P.K. Significance of phytic acid and supplemental phytase in chicken nutrition: a review. World's Poultry Science Journal, v.64, p.553-580, 2008.

SKLAN, D. Development of digestive tract of poultry. World's Poultry Science, v.57, n.4, p.415-428, 2002.

STRADA, E.S.O.; ABREU, R.D.; OLIVEIRA, G.J.C. et al. Uso de enzimas na alimentação de frangos de corte. Revista Brasileira de Zootecnia, v.34, n.6, p.2369-2375, 2005.

TURK, M.; SANDBERG, A.S.; CARLSSON, N.G. et al. Inositol hexaphosphate hydrolysis by baker's yeast, capacity, kinetics and degradation products. Journal of Agricultural and Food Chemistry, v.48, p.100-104, 2000.

VALAJA, J.; PLAAMI, S.; SILJANDER-RASI, H. et al. Effect of microbial phytase on digestibility and utilization of phosphorus and protein in pigs fed wet barley protein with fiber. Animal Feed Science and Technology, v.72, p.221-233, 1998.

VATS, P.; BANERJEE, U. C. Production studies and catalytic properties of phytases (myoinositolhexakisphosphate phosphohydrolases): an overview. Enzyme and Microbial Technology, v.35, n.1, p.3-14, 2004.

WISE, A. Dietary factors determining the biological activity of phytase. Nutrition Abstract and Reviews, v.53, p.791-806, 1983.

YI, Z.; KORNEGAY, E.T.; DENBOW, D.M. et al. Supplemental microbial phytase improves the zinc utilization in broilers. Poultry Science, v.75, p.540-546, 1996. 